\title{
A new chemo-mechanical model of damage in concrete under sulfate attack
}

\author{
Jian-kang Chen ${ }^{\mathrm{a}, \mathrm{b}, *}$, Chen Qian ${ }^{\mathrm{a}}$, Hui Song ${ }^{\mathrm{a}}$ \\ ${ }^{a}$ Mechanics and Materials Science Research Center, Ningbo University, Ningbo, Fenghua Road 818, China \\ ${ }^{\mathrm{b}}$ State Key Laboratory of Nonlinear Mechanics (LNM), Institute of Mechanics, Chinese Academy of Sciences, Beijing, Zhongguancun, China
}

\section{H I G H L I G H T S}

- Damage evolution in concrete under sulfate attack is derived considering chemical reaction rate.

- The characteristic time of chemical reaction represents inflection point of damage evolution.

- Damage nucleation is due to tensile failure at the surface of pores by delayed ettringite.

\section{G R A P H I C A L A B S T R A C T}

The characteristic time $t_{p}$ related chemical reaction rate approximately is the inflection point of damage evolution.

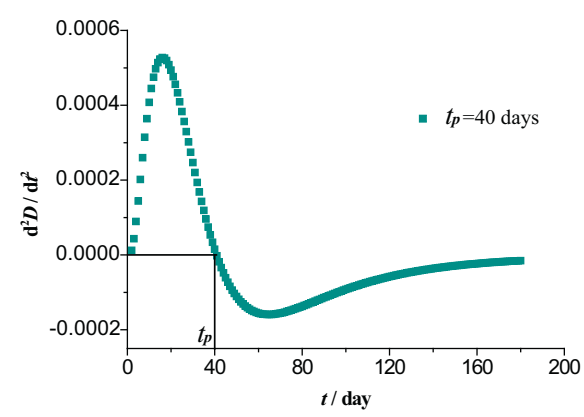

\begin{abstract}
A B S T R A C T
Damage evolution is detected via the degradation of modulus of concrete immersed in sulfate solution. The mechanism of the damage is investigated by using SEM method, and it is proved that the internal expansion stress induced by delayed ettringite leads to the nucleation of micro-cracks. The criterion of damage nucleation is proposed in terms of the tension strength of concrete. The differential equation with respect to the internal expansion stress is derived by virtue of chemical reaction rate on delayed ettringite formation, and a new chemo-mechanical model of corrosion damage in concrete under sulfate attack is then proposed.
\end{abstract}

(c) 2016 Elsevier Ltd. All rights reserved.

Concrete

Sulfate attack

Damage evolution

Chemical reaction

Ultrasonic technique

\section{Introduction}

In the environment of ocean or salt lake, the mechanical properties of concrete structures strongly degrade by attack of harmful ions, such as chloride ions, sulfate ions, magnesian ions, and so on

\footnotetext{
* Corresponding author at: Mechanics and Materials Science Research Center, Ningbo University, Ningbo, Fenghua Road 818, China.

E-mail address: chenjiankang@nbu.edu.cn (J.-k. Chen).
}

$[1,2]$. It is well known that chloride ions dominantly attack reinforcing steel and induce it to corrosion, and magnesian ions react with $\mathrm{C}-\mathrm{S}-\mathrm{H}$ gel, and lead to calcium leaching. The mechanism for the sulfate attack on concrete matrix, however, is so complicated that it is still unclear till now. For instance, Tixier and Mobasher [3] and Ikumi et al. [4] thought that a series of chemical reactions take place between sulfate ions and the unreacted hydration compounds of the cement paste, and all those reactions lead to degradation of concrete. Therefore, this challenge problem attracts many 
researchers' close attention. In fact, people early realized the degradation effect of sulfate in the second half of the nineteenth century, and found sulfate ions diffused in porous of concrete react with pore solution to induce delayed ettringite formation (DEF). DEF leads to the damage evolution under the condition that concrete dose not experience an elevated temperature (e.g. $[5,6])$. Related studies on concrete under sulfate attack dominantly focus on the mechanism of degradation of mechanical properties and material design on sulfate resistance.

Because the degradation mechanism of mechanical properties relates to the delayed ettringite, some of studies focus on the mechanism of DEF $[7,8]$ and crystal structure $[9,10]$. The internal expansion forces are produced under the action of delayed ettringite, and the expansion in concrete occurs due to the internal expansion forces. Barbarulo et al. [11] studied the expansion of concrete during DEF under high temperature and thermal cycle, and found that the expansion strain reaches 3\%. Pavoine et al. [12] further considered the effect of wetting and drying on the expansion of concrete due to DEF, and indicated that the expansion occurs earlier than that in the concrete without wetting and drying condition. Zhang et al. [13] studied the expansion of concrete due to attack of sulfate and sulfate-chloride ions. It was found that the expansion caused by attack of sulfate-chloride ions is much less than that induced only by sulfate attack. The mechanism of such a phenomenon is that DEF in the former situation is much less than that in the latter situation.

Under sulfate attack, the corrosion damage leads to the degradation of stiffness and strength of concrete. Planel et al. [14] studied the long-term behavior of cement mortar, and analyzed sizeeffect on the degradation of mechanical properties of the material. Chen et al. [15] investigated the damage evolution in concrete due to sulfate attack, and suggested an empirical formula of the damage evolution. Rozière et al. [16] not only experimentally analyzed the variation of mass and deformation of concrete exposed to leaching and external sulfate attacks, but also showed some pictures of cracks growth in micro-scale. Because the filling effect of delayed ettringite in pores of concrete, the pore structure is changed. Pipilikaki et al. [17] examined the variation of microstructure of concrete under sulfate attack, meanwhile they also inspected the changes of compressive strength of the material.

In order to improve the property of sulfate resistance of concrete, some researchers adopted new mix design of concrete. For instance, Plowman and Cabrera [18] used fly ash as additive agent to polish up the microstructure of concrete; Chindaprasirt et al. [19] employed both fly ash and rice husk ash as new components of concrete for slowing down degradation of concrete; Lee et al. [20] replaced part of cement by silica fume to reduce the magnitude of delayed ettringite in concrete.

All those method can only slow down the rate of chemical reaction for DEF, however, it is difficult to completely prevent concrete from degradation. Therefore, it is still important to establish a reasonable prediction theory on the service life of concrete structure in marine environment. Kuhl et al. $[21,22]$ suggested a new theoretical frame, which includes the coupling effect of chemistry and mechanics, to analyze the degradation of cementitious materials due to calcium leaching and mechanical damage. Nevertheless, few works on the degradation of concrete under sulfate attack have been reported.

In this paper, variation of dynamic modulus of concrete under sulfate attack was detected by virtue of ultrasonic technique. The average corrosion damage was defined as the relative decrease to the modulus, and it was determined from the experimental results. Then, the damage nucleation due to the action of internal expansion stress, which is produced by delayed ettringite, was analyzed by Eshelby's equivalent inclusion method. Based on the assumption that the expansion stress is directly proportional to the mass of delayed ettringite, the differential equation for the expansion stress is derived by considering the related chemical reaction as well as reaction rate. Finally, a new damage evolution model of concrete is proposed in terms of Weibull's weakest link model.

\section{Experimental}

Reference cement produced by China Building Materials Academy was adopted to form specimens of concrete. The components of the reference cement were listed in Table 1.

Cement-to-sand ratio of the specimens is $1: 2$, and water-to-cement ratio is 0.45 . The shape of the specimens is cylindrical, which are $500 \mathrm{~mm}$ in length and $45 \mathrm{~mm}$ in diameter, respectively. The concrete specimens were cured $24 \mathrm{~h}$ at ambient condition, after then they were put into a concrete standard compartment for curing 28 days, which has the environment temperature of $20^{\circ} \mathrm{C}$ and relative humidity of $90 \%$.

After being cured 28 days, the specimens were moved into the solutions of sodium sulfate, with three different concentrations selected as, $3 \%, 5 \%$, and $8 \%$. During the period of immersion, the ultrasonic detection was carried out, and diagram of the detection was plotted in Fig. 1. When the frequency of ultrasonic is given, the wave propagates from one end of the specimen to the other end with a constant velocity.

In the situation shown in Fig. 1, the ultrasonic propagation is an axisymmetric problem. Just as pointed by Rayleigh, however, if the ratio of radius to wavelength is less 0.7 , then it can be approximately referred to as one dimensional stress [23]. The relation between the elastic modulus, $E$, and the wave velocity, $C$, can be written as follows [24],

$E=C^{2} \rho$

where the symbol " $\rho$ " stands for density of the specimen. If the change of the density and the wave velocity are measured, then the variation of the modulus can be determined by Eq. (1).

By means of weight method, variation of density was measured at different immersion times and plotted in Fig. 2. It can be seen that the density monotonously increases due to a series chemical reactions, including reactions on continued hydration and DEF, etc.

Variation of modulus was measured by virtue of ultrasonic technique shown in Fig. 1, and the results were plotted in Fig. 3. The time interval of the first stage decreases with the increase of the concentration of sulfate solution. It was found that the variation of the modulus can be divided into two stages. In the first stage (initial stage) the modulus increases, but in the second stage it decreases. This implies that the damage evolution only takes place in the second stage, thus, we define that the damage in this stage is the relative decrease of the modulus, i.e.,

$D=1-\frac{E}{E_{\max }}$

where the symbol " $E_{\max }$ " denotes the maximum modulus. From the experimental results in Fig. 3 and Eq. (2), the damage was obtained and plotted in Fig. 4. One can see that damage evolution is more fast in the sulfate solution of higher concentration.

After being immersed for 360 days, the macro-cracks can be observed in specimens as shown in Fig. 5.

For establishing a theoretical model of damage evolution, microscopic observation was performed using SEM technique. Fig. 6 shows the observation of DEF in pores of concrete and related energy spectrum analysis.

\section{Theoretical model of damage evolution}

Damage evolution in concrete can be studied by investigating the crack propagation [25], or predicting statistical evolution of damage by virtue of continuum damage [26]. In this study, a statistic method is adopted to investigate the damage evolution in concrete under sulfate attack. For this, the damage nucleation is studied first.

\subsection{Damage nucleation}

Experimental results indicate that DEF in pores of concrete is a dominant factor to induce the corrosion damage. The mechanism for damage nucleation is that sulfate ions diffused in pores of concrete react with pore solution in concrete, which leads to DEF (as shown in Fig. 7). This process can be divided into two steps: 1) reaction between sulfate ions, $\mathrm{SO}_{4}^{2-}$, and calcium hydroxide, $\mathrm{CH}$, to form gypsum, $\mathrm{CS} \mathrm{H}_{2} ; 2$ ) reaction of gypsum with tricalcium 
Table 1

Components of reference cement.

\begin{tabular}{|c|c|c|c|c|c|c|c|c|c|c|}
\hline $\mathrm{SiO}_{2}$ & $\mathrm{Al}_{2} \mathrm{O}_{3}$ & $\mathrm{Fe}_{2} \mathrm{O}_{3}$ & $\mathrm{CaO}$ & $\mathrm{MgO}$ & $\mathrm{SO}_{3}$ & $\mathrm{Na}_{2} \mathrm{O}_{\text {eq }}$ & LOSS & $\mathrm{f}-\mathrm{CaO}$ & C3S & $\mathrm{C} 3 \mathrm{~A}$ \\
\hline 21.07 & 4.45 & 2.69 & 63.23 & 2.03 & 2.93 & 0.53 & 2.38 & 0.94 & 53.01 & 6.68 \\
\hline
\end{tabular}

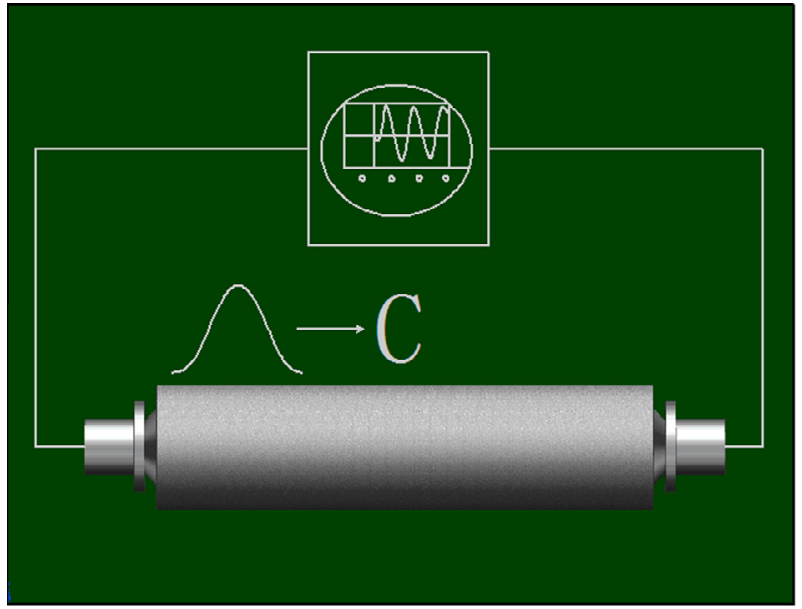

Fig. 1. Diagram of ultrasonic detection.

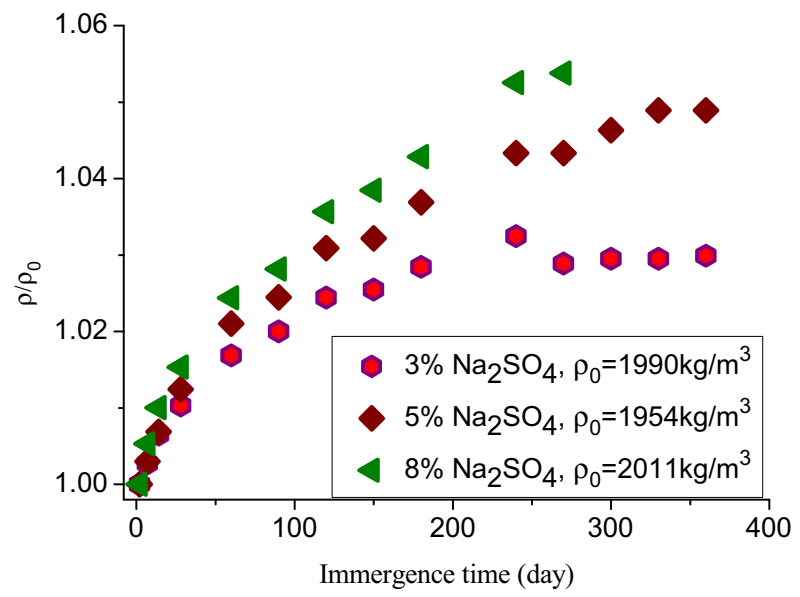

Fig. 2. Evolution of density of concrete under sulfate attack.

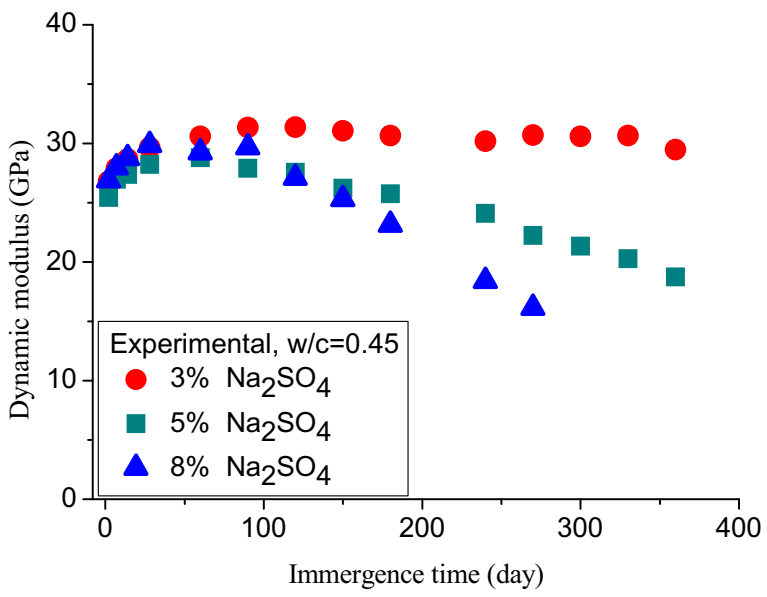

Fig. 3. Evolution of modulus of concrete under sulfate attack.

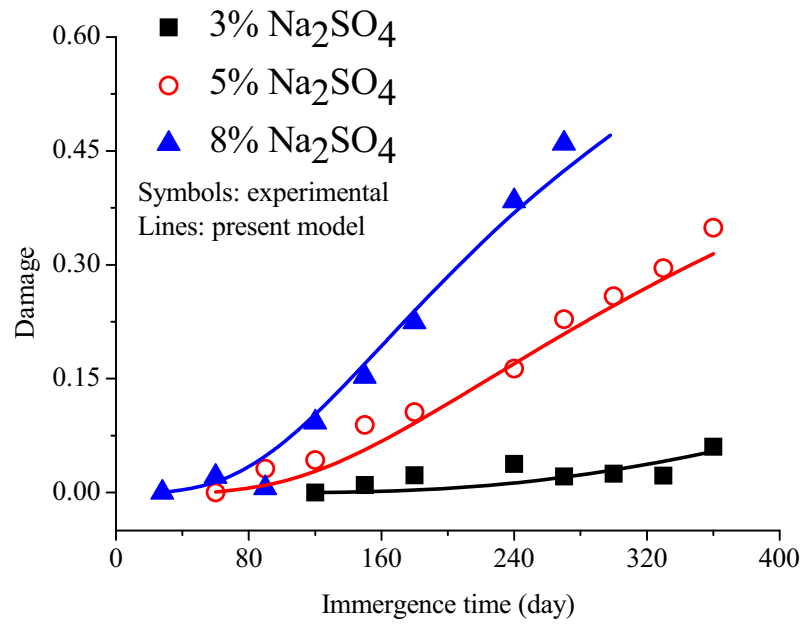

Fig. 4. Damage evolution in specimens under sulfate attack.

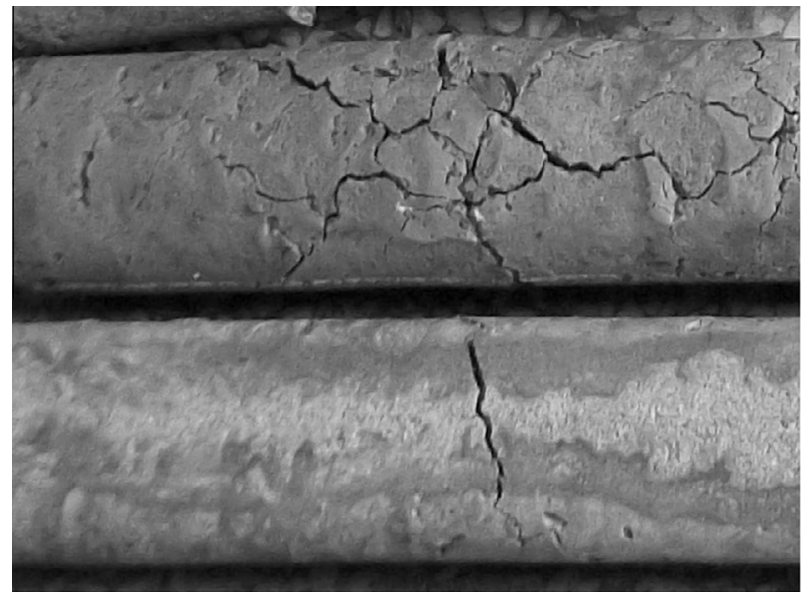

Fig. 5. Macro-cracks in specimens under sulfate attack.

aluminate, $C_{3} A$, and water, $H$, to form delayed ettringite, $C_{6} A_{S_{3}} H_{32}$. Detail chemistry reaction equations are given as follows [4],

$\mathrm{CH}+\mathrm{SO}_{4}^{2-} \longrightarrow \mathrm{CS}_{2}+2 \mathrm{OH}^{-}$

$\mathrm{CA}+q \mathrm{CS} \mathrm{H}_{2} \longrightarrow \mathrm{C}_{6} \mathrm{AS}_{3} \mathrm{H}_{32}$

$\mathrm{CA}:=\gamma_{1} \mathrm{C}_{3} \mathrm{~A}+\gamma_{2} \mathrm{C}_{4} \mathrm{AH}_{13}+\gamma_{3} \mathrm{C}_{4} \mathrm{AS} \mathrm{H}_{12}$

$q=3 \gamma_{1}+3 \gamma_{2}+2 \gamma_{3}$

where symbols " $\mathrm{C}_{4} \mathrm{AH}_{13}$ " and " $\mathrm{C}_{4} \mathrm{AS} \mathrm{H}_{12}$ " respectively represent tetracalcium aluminate and monosulfate; $q$ stands for the stoichiometric weighted coefficient of the sulfate phase; $\gamma_{i}(i=1-3)$ denotes the proportion of each aluminate phase to the total aluminate content.

As shown in Fig. 7, if a pore is filled by the delayed ettringite, expansion stress, $p$, begins to appear, and it produces tensile stress at the surface of the pore. When such a tensile stress reaches the 


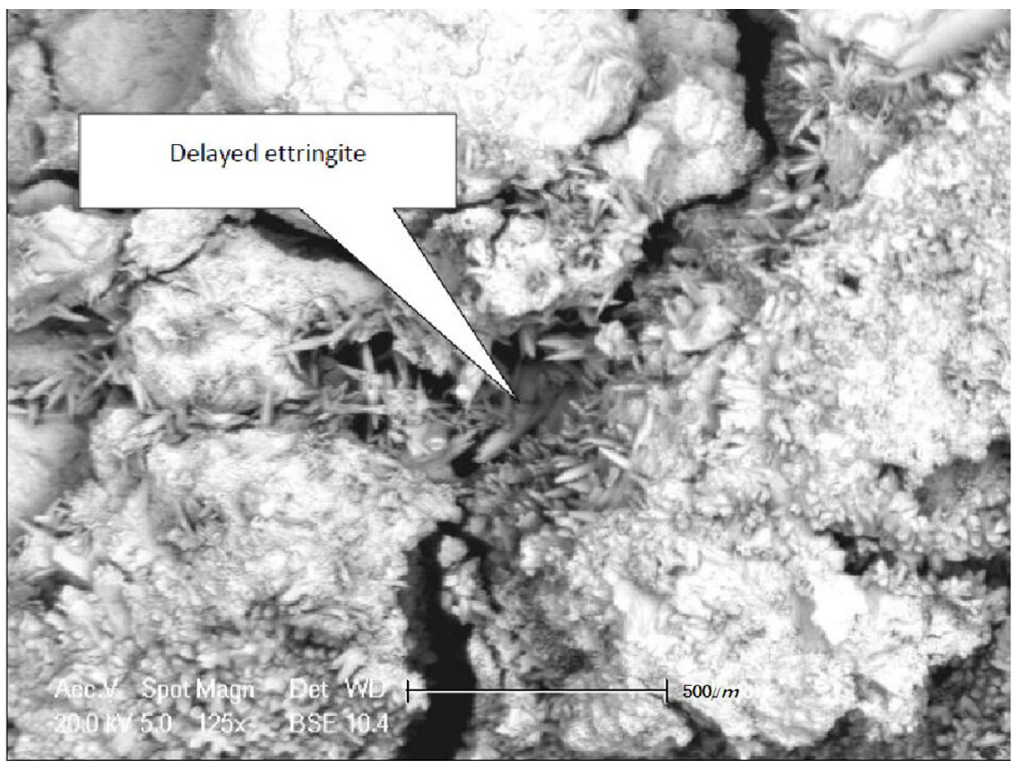

(a)

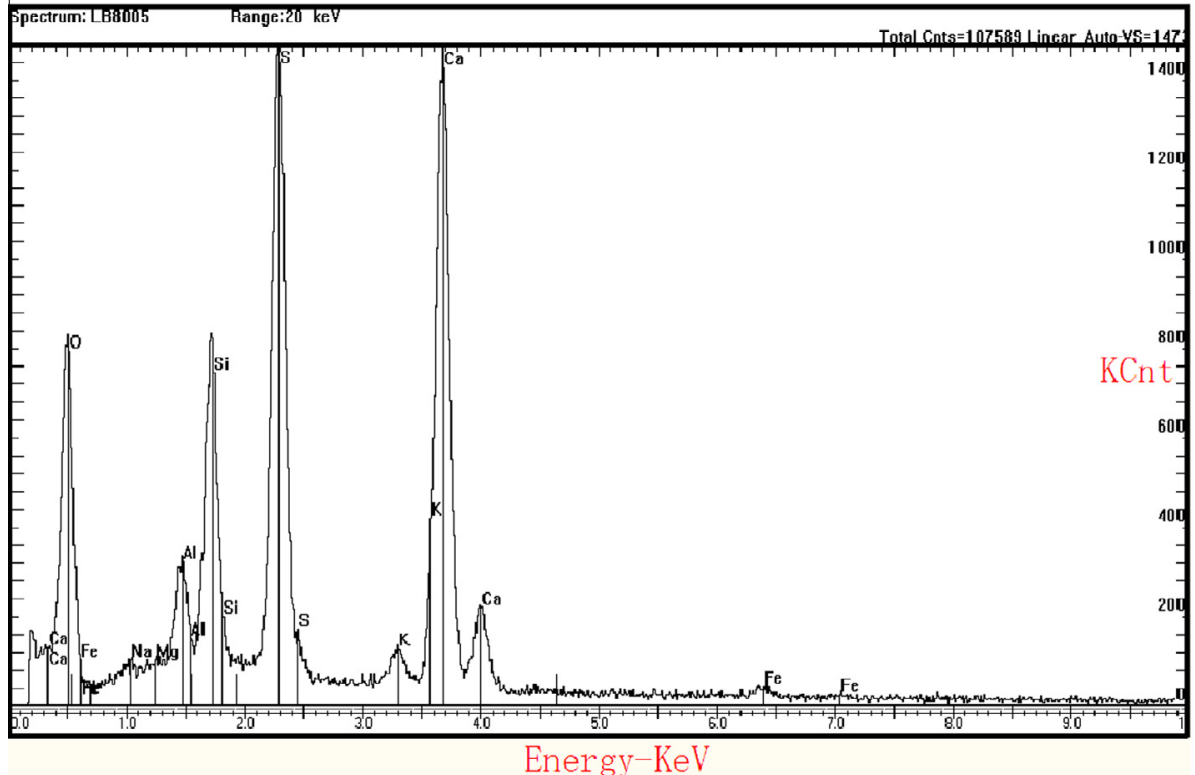

(b)

Fig. 6. Delayed ettringite formation: (a) SEM photo; (b) energy spectrum analysis.

tensile strength of the material, micro-cracks appear, and this is the mechanism of the nucleation of micro-damage. Here, we use the symbol " $p_{\text {cr" }}$ " to denote the critical expansion stress when the nucleation of micro-damage appears. In the following analysis, the Eshelby's equivalent inclusion method [27] is adopted to evaluate $p_{\mathrm{cr}}$.

For convenience, the shape of a pore is approximately assumed to be ellipsoidal void of revolution (shown in Fig. 8), in which the semi-axes of the pore in $x-, y$-, and $z$-directions are denoted by $a_{1}$, $a_{2}$, and $a_{3}\left(a_{1}=a_{2}\right)$, respectively. Usually, the viscous effect of concrete should be taken into account for establishing the constitutive model. In this study, however, the nucleation of micro-cracks is induced by tensile force, and in this situation, the deformation is so small that the constitutive relation of concrete can be approximately assumed to be a linear isotropic elastic one, i.e.,

$\boldsymbol{\sigma}=\mathbf{L}: \boldsymbol{\varepsilon}$

$\mathbf{L}=3 k \mathbf{I}_{\mathrm{m}}+2 \mu \mathbf{I}_{\mathrm{s}}$ where $k$ and $\mu$ are the bulk and shear moduli, respectively, and $\mathbf{I}_{\mathrm{m}}$ and $\mathbf{I}_{s}$ are the fourth order tensors defined by Chen et al. [28],

$\mathbf{I}_{\mathrm{m}}=\mathbf{i}_{0} \otimes \mathbf{i}_{0} / 3, \quad \mathbf{I}_{\mathrm{s}}=\mathbf{I}-\mathbf{I}_{\mathrm{m}}$

where $\mathbf{I}$ and $\mathbf{i}_{0}$ are the fourth order unit tensor and the second order unit tensor, respectively.

In terms of Eshelby's equivalent inclusion method, the relation between the pore strain, $\boldsymbol{\varepsilon}_{\mathrm{p}}$, and the remote strain, $\boldsymbol{\varepsilon}^{\infty}$, can be expressed as [29]

$\boldsymbol{\varepsilon}_{\mathrm{p}}-\boldsymbol{\varepsilon}^{\infty}=\boldsymbol{S}:\left(\boldsymbol{\varepsilon}_{\mathrm{p}}+p \mathbf{J}: \mathbf{i}_{0}\right)$

where $\mathbf{S}$ is the fourth order Eshelby's tensor; $\mathbf{J}$ is the compliance tensor, and

$\mathbf{J}=\mathbf{L}^{-1}=\mathbf{I}_{\mathrm{m}} /(3 k)+\mathbf{I}_{\mathrm{s}} /(2 \mu)$

If there is no external loads, then the remote strain is zero, the relation between $\varepsilon_{\mathrm{p}}$ and p can be expressed by solving Eq. (7) as follows, 


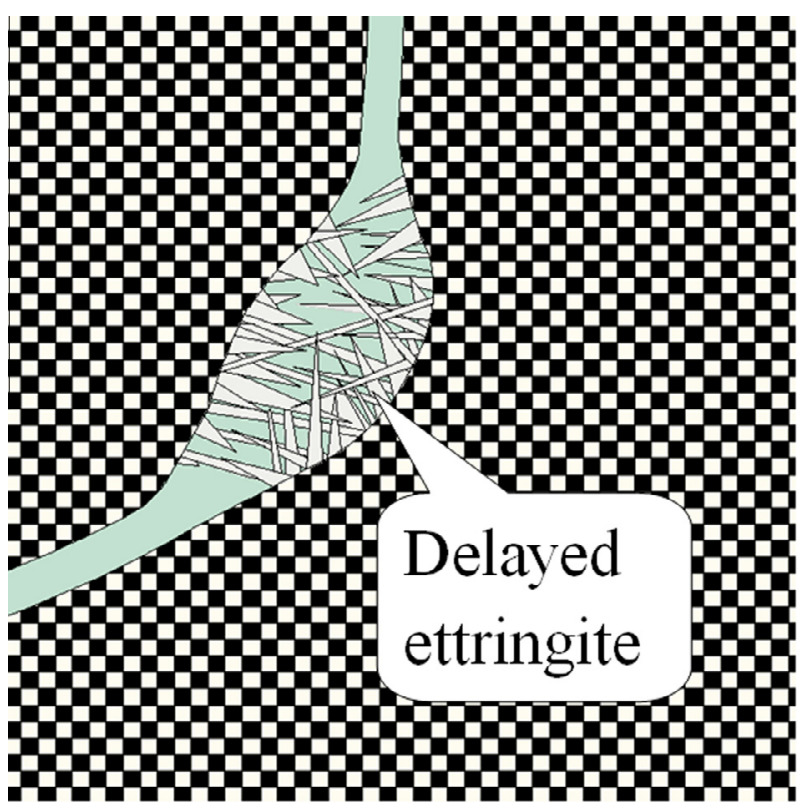

Fig. 7. Plot of delayed ettringite formation in a pore of concrete.

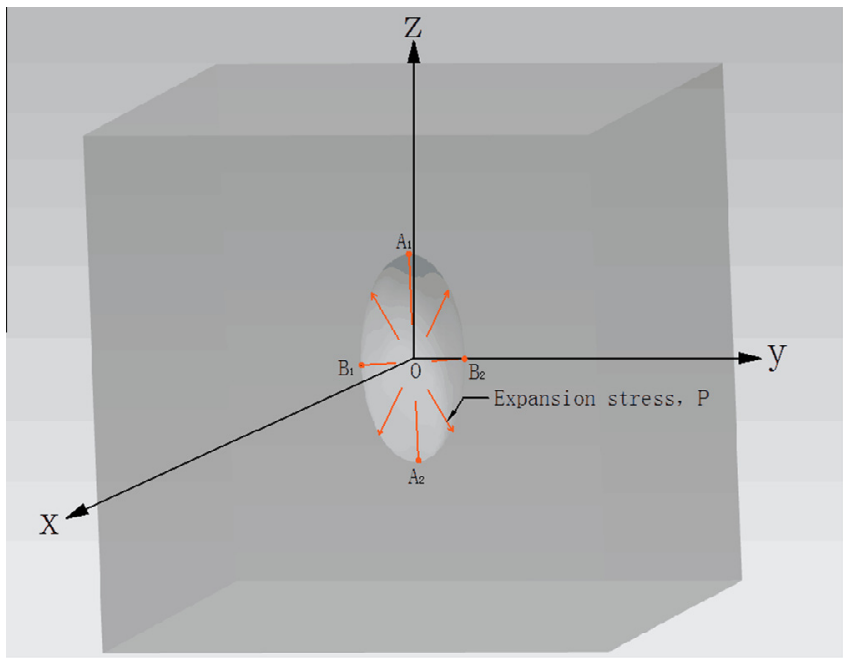

Fig. 8. Plot of a void with expansion stress.

$$
\begin{aligned}
& \boldsymbol{\varepsilon}_{\mathrm{p}}=p \mathbf{g} \\
& \mathbf{g}=(\mathbf{I}-\mathbf{S})^{-1}: \mathbf{S}: \mathbf{J}: \mathbf{i}_{0}
\end{aligned}
$$

Let us now calculate the stress at $A_{1}$ or $A_{2}$, which are the two poles of the void. It is obvious that the stress at point $A_{1}$ is the same as that at $A_{2}$ due to symmetry. Therefore, only stress components at $A_{1}$ are calculated in the following analysis.

According to the boundary condition at the surface and symmetrical property with respect to $z$ axis, i.e.,

$\left.\sigma_{33}\right|_{A 1}=-p$

$\left.\sigma_{11}\right|_{A 1}=\left.\sigma_{22}\right|_{A 1},\left.\quad \varepsilon_{11}\right|_{A 1}=\left.\varepsilon_{22}\right|_{A 1}$

It is easy to obtain the following results,

$\left.\sigma_{11}\right|_{A 1}=\beta p$

$\beta=\left(6 \lambda \mu g_{11}+4 \mu^{2} g_{11}-\lambda\right) /(\lambda+2 \mu)$ where $g_{11}$ can be calculated from Eq. (9).

If $\left.\sigma_{11}\right|_{A 1}$ reaches the tensile strength, $\sigma_{0}$, the damage nucleation occurs, and at this instance, $p$ reaches the critical expansion stress, $p_{\mathrm{cr}}$. Therefore, we obtain,

$p_{\mathrm{cr}}=\beta^{-1} \sigma_{0}$

Eq. (13) gives the relation between the critical expansion stress and the tensile strength of concrete. If the Poisson's ratio $v=0.18$, and the shape of the pore is spherical, then $\beta=0.159$.

\subsection{Evolution of expansive stress}

It can be realized that the development of expansion stress depends on the increase speed of delayed ettringite, which relates to the rate of chemistry reaction. The concentration of $\mathrm{SO}_{4}^{2-}$ and $\mathrm{C}_{3} \mathrm{~A}$ is denoted by symbols " $\mathrm{C}_{\mathrm{SO}}$ " and " $\mathrm{C}_{\mathrm{CA}}$ ", respectively, then the chemical reaction rate equation for Eqs. (3) and (4) is given by Tixier and Mobasher [3],

$$
\begin{aligned}
\frac{\mathrm{dC}_{\mathrm{CA}}}{\mathrm{d} t} & =-\frac{k \mathrm{C}_{\mathrm{CA}} \mathrm{C}_{\mathrm{SO}}}{q} \\
\frac{\mathrm{d} \mathrm{C}_{\mathrm{SO}}}{\mathrm{d} t} & =-k \mathrm{C}_{\mathrm{CA}} \mathrm{C}_{\mathrm{SO}}
\end{aligned}
$$

where $k$ is the coefficient of reaction. Form Eq. (14) we obtain,

Solving Eq. (14) we obtain,

$\mathrm{C}_{\mathrm{SO}}=q \mathrm{C}_{\mathrm{CA}}$

Substituting Eq. (15) into Eq. (14) yields,

$\frac{\mathrm{dC}_{\mathrm{CA}}}{\mathrm{d} t}=-k \mathrm{C}_{\mathrm{CA}}^{2}$

It is well known that expansive stress depends on the amount of delayed ettringite, for simplicity, it is approximately assumed that the increment increase of the expansive stress, $\mathrm{d} p$, is directly proportional to the increase of concentration of delayed ettringite, $\mathrm{dC}_{\text {ettringite, }}$ i.e.,

$\mathrm{d} p \propto \mathrm{dC}_{\text {ettringite }}$

Eq. (4) indicates that the increase of concentration of delayed ettringite is directly proportional to the decrease of concentration, $\mathrm{dC}_{\mathrm{CA}}$, i.e.,

$\mathrm{dC}_{\text {ettringite }} \propto-\mathrm{dC}_{\mathrm{CA}}$

From Eqs. (17) and (18) we obtain,

$\mathrm{dC}_{\mathrm{CA}}=-\lambda \mathrm{d} p$

or

$\mathrm{C}_{\mathrm{CA}}=-\lambda\left(p-p^{*}\right)$

where $\lambda$ and $p^{*}$ are the parameters to be determined.

Substituting Eq. (19) into Eq. (16) we obtain,

$\frac{d \mathrm{p}}{d \mathrm{t}}=k \lambda\left(p-p^{*}\right)^{2}$

Eq. (20) is the evolution equation of expansive stress. Solving Eq. (20) for $p$ we obtain,

$$
\begin{aligned}
& p=p^{*} \frac{t / t_{p}}{1+t / t_{p}} \\
& t_{p}=1 /(k \lambda)
\end{aligned}
$$

where $t_{p}$ is a characteristic time to be determined, which is related to the coefficient of the reaction rate, $k$. Eq. (21) gives an evolution function of expansive stress. 


\subsection{Model of damage evolution}

According to the previous analysis, the damage evolution of concrete under sulfate attack is induced by tensile stress at the surface of pores. Under tensile loading, concrete possesses brittle characteristic, hence, damage evolution can be described by weakest-link theory $[30,31]$. Therefore, we assume that the damage evolution obeys Weibull's distribution function, i.e.,

$D=1-\exp \left[-\left(\frac{p-p_{c r}}{p_{u}}\right)^{m}\right], \quad\left(p \geqslant p_{c r}\right)$

where $m$ and $p_{u}$ are the parameters to be determined, and $p_{c r}$ is determined by Eq. (13).

Substituting Eqs. (21), (22) yields,

$D=1-\exp \left[-\left(\frac{p^{*} \frac{t / t_{p}}{1+t / t_{p}}-p_{c r}}{p_{u}}\right)^{m}\right]$

If the damage nucleation occurs at a critical instant $t_{c r}$, then from Eq. (23) we obtain,

$p_{c r}=p^{*} \frac{t_{c r} / t_{p}}{1+t_{c r} / t_{p}}$

The critical nucleation time, $t_{c r}$, is directly determined by experimental results shown in Fig. 4, which is the initial instant for damage evolution. The values of $t_{c r}$ are listed in Table 2 .

Substituting Eq. (24) into Eq. (23), we obtain a new model of damage evolution as follows,

$$
\begin{aligned}
& D=1-\exp \left\{-\left[\gamma\left(\frac{t / t_{p}}{1+t / t_{p}}-\frac{t_{c r} / t_{p}}{1+t_{c r} / t_{p}}\right)\right]^{m}\right\}, \quad\left(t \geqslant t_{c r}\right) \\
& \gamma=\frac{p^{*}}{p_{u}}
\end{aligned}
$$

There are only three parameters in Eq. (25), $\gamma, t_{p}$, and $m$, that need be determined. The rate of reaction is represented by the characteristic time $t_{p}$. All parameters are determined according to the experimental results by using a curve fitting method, the values of which are listed in Table 2.

\section{Discussion}

Most researches on the problems of concrete under sulfate attack dominantly attributed the degradation mechanism to the action of delayed ettringite, which was observed in micro-cracks. Perhaps some people argue that such micro-cracks are induced by other factors, such as carbonation, drying and wetting cycle, freezing and thawing cycle, attack of chloride ions, or original defects in concrete, and those defects supply space for delayed ettringite formation and growth. Hence, they consider that delayed ettringite dose not cause such a degradation of concrete. In this study, the experiment design excludes those factors. For instance, specimens are formed by cement mortar, and there is no aggregate in the material (for reducing the original defects), and the specimens were immersed in sulfate solution at room temperature

Table 2

Parameters of damage model.

\begin{tabular}{lllll}
\hline Parameters/concentration $(\%)$ & $t_{c r}$ (day) & $\gamma$ & $m$ & $t_{p}$ (day) \\
\hline 3 & 120 & 1.5 & 4.236 & 350 \\
5 & 60 & 1.5 & 4.236 & 113.6 \\
8 & 28 & 1.5 & 4.236 & 104.9 \\
\hline
\end{tabular}

(there are no carbonation, drying and wetting cycle, freezing and thawing cycle, and attack of chloride ions involved). Nevertheless, the macro-cracks and micro-cracks were still observed (shown in Figs. 5 and 6), and this result confirms again that the action of delayed ettringite is the dominant factor for the degradation of concrete.

Experimental results also indicate that the degradation of concrete under sulfate attack dose not occurs in the initial stage of sulfate attack process. Contrarily, it was found that in this stage the modulus of concrete increases (shown in Fig. 3). This is because the continuous hydration, which leads to increase of C-S-H gel and repairs the original defects in concrete, and enhance the modulus and strength of the material. Otherwise, the filling effect of DEF can reduce the porosity of concrete, which leads to the increase of modulus.

In the new model for corrosion damage evolution, $\gamma$ is a nondimensional loading coefficient defined by Eq. (25), and $m$ is a non-dimensional parameter. They are all constant if the material is determined, and this is because the effect of the concentration of sulfate solution on the damage evolution has been denoted by $t_{c r}$ and $t_{p}$. Other parameter, i.e., the characteristic time, $t_{p}$, however, changes with the concentration of sulfate solution. This indicates that the rate of chemical reaction strongly affects the damage evolution. Eq. (21) shows that $t_{p}$ depends on the coefficient of reaction, $k$. The faster the reaction, the shorter the characteristic time. In order to discuss the effect of such a characteristic time, the numerical calculation is performed. For convenience, we take $\gamma=1.5$, $m=4.236$, and the effect of critical nucleation time on the damage evolution is ignored in the calculation. The results are plotted in Fig. 9. It can be seen that the damage evolution decreases with the increase of $t_{p}$. The numerical results of the second derivative of damage with respect to time, $\mathrm{d}^{2} D / \mathrm{d} t^{2}$, were plotted in Fig. 10. One can see that $\mathrm{d}^{2} D / \mathrm{d} t^{2}$ approximately equals zero if $t=t_{p}$, which means that $t_{p}$ can be referred to the inflection point of damage evolution.

The damage evolution starts from the critical nucleation time, $t_{c r}$, which depends on the tensile strength of concrete (see Eqs. (13) and (24)). If the tensile strength of concrete is enhanced, then the speed of corrosion damage is slowed down. In terms of this sequitur, we suggest a new method for improving sulfate resistance of concrete; that is to add short fibers into concrete. The tensile strength of concrete is enhanced in this way [32], while the sulfate attack induced damage is effectively reduced.

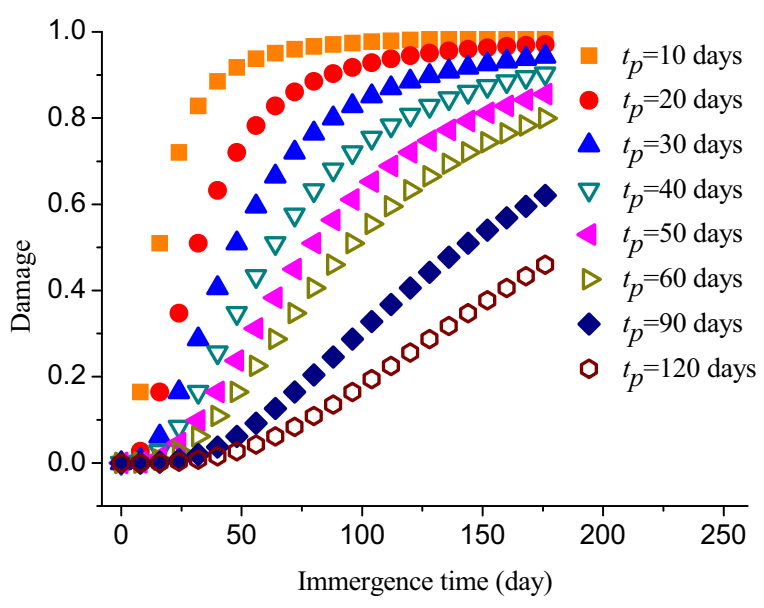

Fig. 9. Effect of $t_{p}$ on damage evolution. 


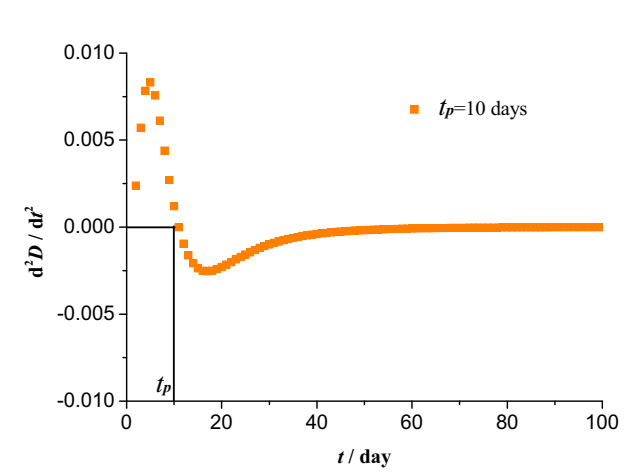

(a)

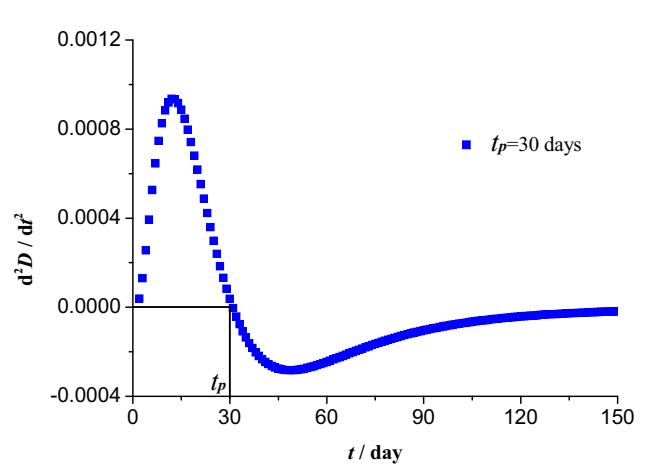

(c)

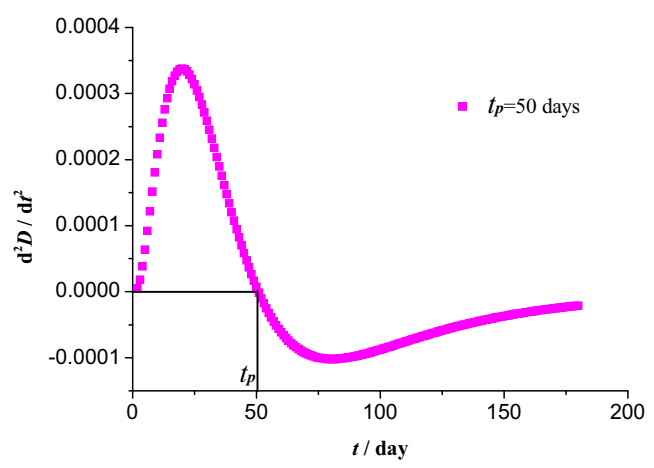

(e)

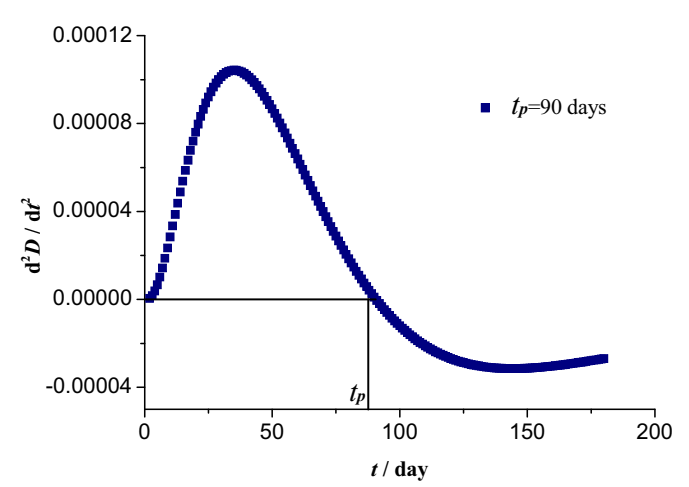

(g)

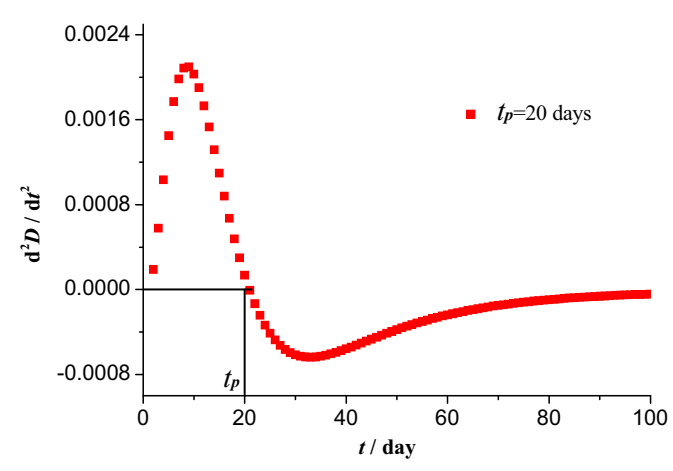

(b)

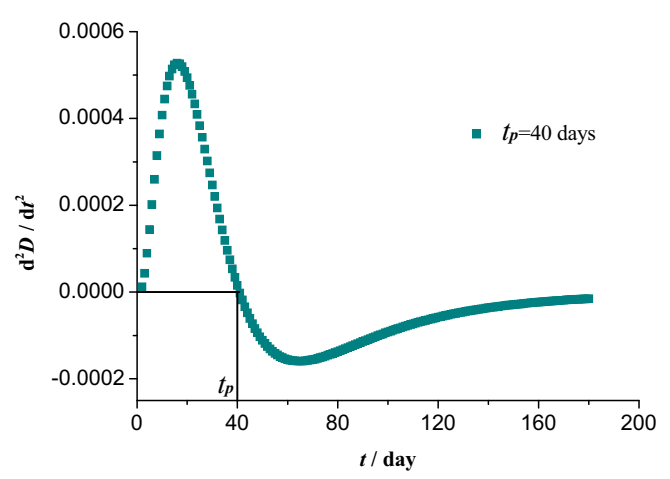

(d)

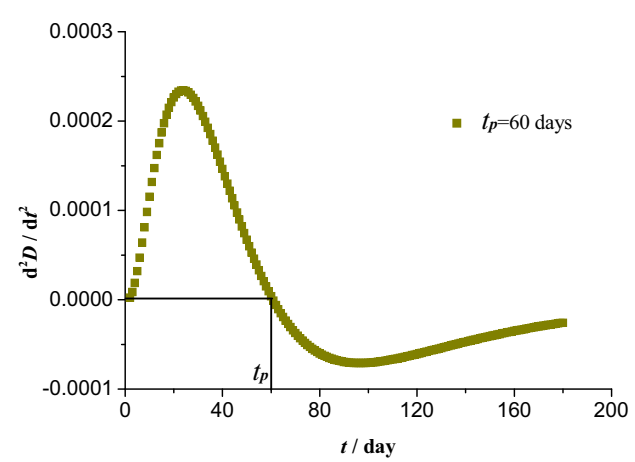

(f)

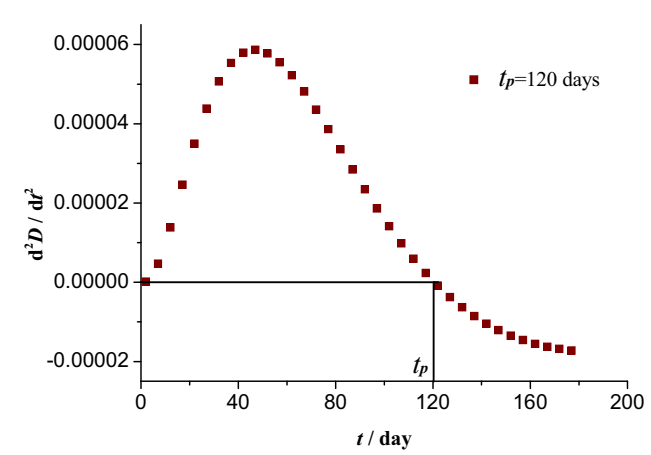

(h)

Fig. 10. Plot of $\mathrm{d}^{2} D / \mathrm{d} t^{2} \sim t$ curves. 


\section{Conclusions}

In this paper, the damage evolution in concrete under sulfate attack is investigated. The experimental results confirm that the expansion stress induced by delayed ettringite is the dominant mechanism for the degradation of concrete. The damage evolution can be divided into two stages, and the elastic modulus of concrete dose not decrease but increases in the first stage. This phenomenon is caused by continuous hydration and the filling effect of delayed ettringite. The mechanism for damage nucleation is analyzed by using Eshelby's equivalent inclusion method. It is found that the tensile stress due to the action of expansive stress produced by delayed ettringite leads to nucleation of micro-cracks. By virtue of this opinion, a new method is proposed, i.e., to increase the tensile strength by adding short fibers for improving the sulfate resistance of concrete. Based on the experimental results, as well as chemical reaction and reaction rate equation, we derive a differential equation for governing the evolution of expansive stress. By assuming that the damage variation obeys Weibull's distribution function, we proposed a new model of damage evolution, which can be used to properly describe the characteristics of corrosion damage of concrete under sulfate attack. The methods used in this study are valid for establishing the strength evolution of concrete attacked by sulfate or other corrosion environment.

\section{Acknowledgments}

The financial support by National Natural Science Foundation of China (NSFC \# 51079069), the Key Research Program of Society Development of Ningbo (2013C51007), the National Basic Research Program of China (973 Program, 2009CB623203), and K.C. Wong Magna Fund in Ningbo University are gratefully acknowledged.

\section{References}

[1] R.D. Moser, P.M. Singh, L.F. Kahn, K.E. Kurtis, Chloride-induced corrosion resistance of high-strength stainless steels in simulated alkaline and carbonated concrete pore solutions, Corros. Sci. 57 (2012) 241-253.

[2] S. Muthulingam, B.N. Rao, Non-uniform corrosion states of rebar in concrete under chloride environment, Corros. Sci. 93 (2015) 267-282.

[3] R. Tixier, B. Mobasher, Modeling of damage in cement-based materials subjected to external sulfate attack. I: formulation, J. Mater. Civil Eng. 15 (2003) 314-322.

[4] T. Ikumi, S.H.P. Cavalaro, I. Segura, A. Aguado, Alternative methodology to consider damage and expansions in external sulfate attack modeling, Cem. Concr. Res. 63 (2014) 105-116.

[5] S. Diamond, Delayed ettringite formation-processes and problems, Cem. Concr. Compos. 18 (1996) 205-215.

[6] M. Collepardi, Thaumasite formation and deterioration in historic buildings, Cem. Concr. Compos. 21 (1999) 147-154.
[7] R. Yang, C.D. Lawrence, C.J. Lynsdale, J.H. Sharp, Delayed ettringite formation in heat-cured Portland cement mortars, Cem. Concr. Res. 29 (1999) 17-25.

[8] W. Prince, M. Espangne, P.C. Aitcin, Ettringite formation: a crucial step in cement super plasticizer compatibility, Cem. Concr. Res. 33 (2003) 635-641.

[9] A.E. Moore, H.F.W. Taylor, Crystal structure of ettringite, Acta Crystallogr. B26 (1970) 386-390.

[10] K.L. Scrivener, H.F.W. Taylor, Delayed ettringite formation: a microstructural and microanalytical study, Adv. Cem. Res. 8 (1996) 11-19.

[11] R. Barbarulo, H. Peycelon, S.J. Prené Marchand, Delayed ettringite formation symptoms on mortars induced by high temperature due to cement heat of hydration or late thermal cycle, Cem. Concr. Res. 35 (2005) 125-131.

[12] A. Pavoine, L. Divet, S. Fenouillet, A concrete performance test for delayed ettringite formation: Part I optimisation, Cem. Concr. Res. 36 (2006) 21382143.

[13] M.H. Zhang, J.K. Chen, Y.F. Lv, D.J. Wang, J. Ye, Study on the expansion of concrete under attack of sulfate and sulfate-chloride ions, Constr. Build. Mater. 39 (2013) 26-32.

[14] D. Planel, J. Sercombe, P. Le Bescop, F. Adenot, J.M. Torrenti, Long-term performance of cement paste during combined calcium leaching-sulfate attack: kinetics and size effect, Cem. Concr. Res. 36 (2006) 137-143.

[15] J.K. Chen, M.Q. Jiang, J. Zhu, Damage evolution in cement mortar due to corrosion of sulphate, Corros. Sci. 50 (2008) 2478-2483.

[16] E. Rozière, A. Loukili, R. El Hachem, F. Grondin, Durability of concrete exposed to leaching and external sulphate attacks, Cem. Concr. Res. 39 (2009) 11881198.

[17] P. Pipilikaki, D. Papageorgiou, M. Dimitroula, E. Chaniotakis, M. Katsioti, Microstructure changes in mortars attacked by sulfates at 50C, Constr. Build. Mater. 23 (2009) 2259-2264.

[18] C. Plowman, J.G. Cabrera, The use of fly ash to improve the sulfate resistance of concrete, Waste Manage. 16 (1996) 145-149.

[19] P. Chindaprasirt, P. Kanchanda, A. Sathonsaowaphak, H.T. Cao, Sulfate resistance of blended cements containing fly ash and rice husk ash, Constr. Build. Mater. 21 (2007) 1356-1361.

[20] S.T. Lee, H.Y. Moon, R.N. Swamy, Sulfate attack and role of silica fume in resisting strength loss, Cem. Concr. Compos. 27 (2005) 65-76.

[21] D. Kuhl, F. Bangert, G. Meschke, Coupled chemo-mechanical deterioration of cementitious materials Part I: modeling. Int. J. Solids Struct. 41 (2004) 15-40.

[22] D. Kuhl, F. Bangert, G. Meschke, Coupled chemo-mechanical deterioration of cementitious materials Part II: numerical methods and simulations, Int. J. Solids Struct. 41 (2004) 41-67.

[23] L. Rayleigh, Theory of Sound, Dover, New York, 1894

[24] M.A. Meyers, Dynamic Behavior of Materials, John Wiley, Chichester, 1994.

[25] A.S.E. Nassef, Fibonacci sequence and golden ratio in new formula of predicting cracks propagation in reinforced concrete tie, Int. J. Damage Mech. 24 (2015) 1214-1226.

[26] M. Ganjiani, R. Naghdabadi, M. Asghari, Analysis of concrete pressure vessels in the framework of continuum damage mechanics, Int. J. Damage Mech. 21 (2012) 843-870

[27] J.D. Eshelby, The determination of the elastic field of an ellipsoidal inclusion and related problems, Proc. R. Soc. Lond. A241 (1957) 376-396.

[28] J.K. Chen, W.C. Wang, Z.P. Huang, Surface energy effect on damage evolution in a viscoelastic nanocomposite, Int. J. Damage Mech. 19 (2010) 949-970.

[29] J.K. Chen, G.T. Wang, Z.Z. Yu, Z.P. Huang, Y.W. Mai, Critical particle size for interfacial debonding in polymer/nanoparticle composites, Compos. Sci. Technol. 70 (2010) 861-872.

[30] C. Lu, R. Danzer, F.D. Fischer, Influence of threshold stress on the estimation of the Weibull statistics, J. Am. Ceram. Soc. 85 (2002) 1640-1642.

[31] C. Lu, R. Danzer, F.D. Fischer, Fracture statistics of brittle materials: Weibull or normal distribution, Phys. Rev. E 65 (2002) 067102.

[32] P.W. Chen, D.D.L. Chung, Concrete reinforced with up to 0.2 vol.\% of short carbon fibers, Composites 24 (1993) 33-52. 